\title{
How can Disaster Risk Reduction Reduce Inequality? A Study on the Vulnerable Communities of Bangladesh
}

\author{
Nushrat Tashmin \\ Department of Disaster Science and Management, University of Dhaka, Dhaka 1000, Bangladesh \\ Manuscript received: 12 August 2021; accepted for publication: 15 November 2021
}

\begin{abstract}
The present paper deals with the capacity issues of the vulnerable communities of Bangladesh where hazards accelerate the persistent situation on social inequalities. Bangladesh is prone to natural disasters and the persistent socio-economic inequalities tend to increase due to the disaster risks. Disaster risks then hinder the opportunities of the vulnerable communities to become resilient. In this research the researcher has used both secondary and primary data. The researcher has mainly used the secondary data to explore the link between disaster risk reduction and social inequalities. Moreover, the researcher has collected the primary data by using the key informant interview method to have insights of the experts who have shared their valuable views on the relationship between the effective DRR strategies and its potential to reduce the existing social inequalities. The result of the research reveals that the lack of capacity of the disaster vulnerable communities of Bangladesh traps them into further poverty where they buffer their loss and damages with their limited resources. In Bangladesh it is the poor who are the victims of socio-economic inequality and suffer worst from natural disasters. This situation of disaster and poverty becomes a cycle of trap in which the poor tend to suffer and becomes vulnerable. DRR strategies do have the potential to have a positive impact in this scenario. Effective DRR strategies might lead to increase the capacity of vulnerable communities of Bangladesh and the communities will be more resilient.
\end{abstract}

Keywords: DRR; Vulnerability; Inequality; Inclusiveness; Poverty alleviation

\section{INTRODUCTION}

Disaster vulnerability generally comprises both physical conditions and social context which determine the capacity of the communities. As we know that the disaster risks denotes both hazard and vulnerability but it is ultimately determined by the capacity of the communities. Communities which have more capacity the chances become high for them to be resilient. So here comes the factors of social inequality which prevails in societies and it is generally the poor who are the worst victims of different forms of social inequalities. The damage and loss of disasters on low -income households are more intensified. Impoverished families in Bangladesh are more likely to live in the disaster-prone areas and have fewer capacities to spend in risk reduction activities. Due to the persistent socio-economic inequality structure on Bangladesh, there is always lack of access to the social protection especially for the poor and vulnerable communities. So, the damage and loss due

Corresponding author: Nushrat Tashmin

Email: nushrat.dsm@du.ac.bd

DOI: https://doi.org/10.3329/dujees.v10i2.57516 to the disasters buffer the impacts of disasters and this situation obstructs the resilience capacity ultimately.

Bangladesh is a developing country where the levels of rural poverty is high and is extremely prone to natural hazards, such as: flood, cyclone, drought and river bank erosion (Beck, 2005). Eighty percent of the country's population is exposed to floods and droughts and about $70 \%$ are exposed to cyclones. On an average Bangladesh experience severe cyclone every three years and 25\% of the land is inundated every year. Extreme flooding occurs every 4-5 years and covers 60\% of the land (World Bank Press Release, 2018). In last few decades disaster mortality rate has been reduced in Bangladesh though disaster losses tend to continue in a larger scale because of the increased recurrence of natural disasters due to climate change (Ahmed, et al., 2015). As Bangladesh is one of the most populous countries of the worlds, the demographic transition stage is predicted to be obtained in between $2025-2030$ and this can boost the present situation of the socio-economic inequality situation. Presently more than 6 million people are being compelled to migrate due to the loss of livelihoods due to flooding and extreme weather and this number could be doubled by 2050 and the situation will be more complex to handle. Increased 
frequency of disasters has negative impacts not only to the economy but also to the access to education, livelihood, food security, health care and other service provisions. Impacts of natural disasters such as: flooding, cyclones, storm surges, landslides and droughts do a large-scale destruction to life, property, and livelihood of the vulnerable communities and increase the displacement rate every year. Climate change impacts such as: increased frequency of disasters, salinity intrusion, pollution and prolonged droughts have also negatively affected agricultural production, irrigation and fishing and lead toward the food insecurity (UNDRR, 2020). So, the vulnerable situation due to the natural disasters usually sharpens the issues of inequality that affects the lives of the people during non-disaster periods too. Here the concept of vulnerability is also produced and influenced socially which reflect the factors of failures of capacity and increase the overall risk of the communities. As a result, the vulnerable communities tend to become more vulnerable and trapped and can never be able to bounce back to their pre-disaster situations (ACS AEC, 2017).

Disaster risk reduction (DRR) generally means to reduce disaster risks through different efforts to analyze and reduce their causes of risks. In Bangladesh Disaster risk reduction (DRR) is definitely an integral part of social and economic development which can lead toward achieving sustainable development goals (UNDRR, 2021). Here we can see the efforts of emergency responses and the post disaster recovery and rehabilitation. But for effective DRR there should be the constant focus on prevention and mitigation measures too. This will lead to have a large impact on the lives of the people of the vulnerable communities who are at risk. This DRR have a high potential to break the cycle of the trap of persistent socio-economic inequalities of Bangladesh.

In this paper the broad objective was to explore the link between this effective DRR and inequality situation of the country from the socio-economic point of view. So, the research questions here were: a) Do the effective DRR strategies have the capacity to reduce the persistent inequality situation of the disaster-prone vulnerable communities of Bangladesh? b) Can DRR be an integral part of the sustainable socio-economic development of the disaster-prone areas? Disasters cannot be avoided but it can be averted through the reduced exposure of communities to risk by increasing their capacities to resist it and this will lead towards the reduction of their vulnerability. The paper reveals that in Bangladesh, mainstreaming DRR into development planning and action can effectively protect people and their assets from the disaster impacts.

\section{METHODOLOGY}

In this research the researcher has used both secondary and primary data. Here the researcher has mainly used the secondary data analysis method by using data from different secondary literatures available on DRR and inequalities in Bangladesh. At first the literatures were synthesized and then the researcher highlighted the results to explore the link between disaster, poverty and inequalities and this was the main objective of this study.

To select the literatures for secondary data analysis, the researchers first set the context the broad field of study. Here the broad field to select the literature was Disaster Risk Reduction (DRR) and Inequality scenario of Bangladesh. Researcher set the database comprised of the data set and findings of recent studies regarding the DRR and its relationship to poverty and inequality situation of the disasterprone areas of Bangladesh. To select the sample literature the relevant keywords were used to search, such as: Disaster Risk Reduction, Inequality, Socioeconomic Inequality, Poverty and Disaster in Bangladesh and so on. Then to check the reliability and validness for sample selection the researcher has checked each and every source. The researcher has analyzed the secondary data of the last 20 years to validate the research problem of the present study. Emphasis is given from the past to recent data to attain the objectives of this research. The literature review timeframe of this paper is divided into three phases. The initial review was done in between January to April of 2021 while contextualizing the research problem. The second phase was done in between May to July of 2021 during the data collection and processing. The final phase was done in between August to October of 2021 while analyzing the data and the final write-up of the paper.

To have detailed, practical and empirical evidence the researcher has collected the first-hand primary data through some intense key informant interviews (KII) with experts, policy makers and stakeholders. 
Respondents were selected on a purposive basis. Twelve experts (academicians, development workers and policy makers) were selected as key informant who has in-depth insights on DRR and socioeconomic inequality of Bangladesh. Researchers collected information from them through some faceto-face semi-structured interview sessions and also through some interviews over the phone. Each of the face-to-face interview sessions were about one and half hour long and they were recorded in the smartphones. Interviews over the phone were done on the need basis. Moreover, the researcher has analyzed some case studies from secondary sources for empirical examples on the link between disaster risk reduction and minimization of inequalities.

After collecting all the necessary data from both secondary and primary sources the researcher then analyzed and articulated the findings to detailed insights on the objective of the present study. Researcher analyzed the qualitative data through the emergent process in which the findings, research questions, objectives, theoretical framework and conceptualization of terms are measured through the changes over the course of different literatures. The findings are presented here thematically as the way they were actually analyzed. The intense analysis led the researcher to sum up the discussion and to provide some effective and relevant recommendations.

\section{BACKGROUND}

\section{Disaster and Inequality Situation in Bangladesh}

In Bangladesh the prevailing structure of poverty is buffered due to the effects of natural disasters. Natural disasters increase and intensify the inequality situations and the vulnerable communities become more vulnerable and lack their capacity to become resilient. In Bangladesh, the general axes of inequality are: class, gender, age and disability. The situation of inequality becomes worse during and after the disaster situation.

The report titled 'Disaster Management Reference Handbook' by Center for Excellence in Disaster Management and Humanitarian Assistance (CFE-DM) highlighted the overall disaster management scenario of Bangladesh. The report was published in 2020. In this report there is a detailed overview of the disaster management structure of the country and it presents the inequality situation in terms of vulnerable population and their situation of poverty, water supply, hygiene, sanitation and other humanitarian issues. This report demonstrates that the geographic location of Bangladesh makes it vulnerable to natural disasters. According to this report "from 1970-2019, storms have been the most frequent disaster to affect Bangladesh at 52\%, followed by flood, at $31 \%$ with the remaining disasters being epidemics, earthquakes, droughts, and landslides" (CFE-DM, 2020). In terms of natural disasters, Bangladesh was ranked as $8^{\text {th }}$ worst-hit country as per the report of 2018 as 37 million people were affected by natural disasters in the previous ten years. The report also revealed that in 2018 approximately $21.8 \%$ people lived below poverty line. The disaster situation has a direct impact on the poverty situation of the country where the vulnerable communities are tending to be the worst victims of inequality.

Khondker (2014) highlighted the poverty profiles of different vulnerable groups of Bangladesh. In this paper the researcher highlighted that, the rate of poverty is higher in rural areas compared to the urban. Also, the paper highlighted that the female headed households are poorer than male headed households and the households with the old age people and disable members are also vulnerable and tend to go through difficulties during and after shocks such as: natural disasters. According to this paper, the Bureau of Statistics (BBS) stated that the inequality situation of the country is steady and very high with the Gini coefficient at 0.46 when income is measured in the year 2010. The researcher concluded the paper by highlighting the importance social protection measures which need to be conceptualized and delivered (Khondker, 2014).

The status report of UNDRR states that, the geographic location of Bangladesh is susceptible to various hazards and these hazards do have the potential to affect the assets of the country. Besides, the disasters are also affecting livelihoods of the vulnerable communities. These impacts have negatively affected the livelihoods of the communities who are engaged in different small-scale agricultural works and the people who are involved in informal economic sectors. Along with economy disasters have social impacts too. Disasters negatively affect the access to education, housing, food security and livelihood opportunities, (UNDRR, 2020). So, this situation is widening the gaps and the polarization is 
becoming evident. Moreover, the air and river pollution, coastal degradation and destruction of mangroves also affect the low-income population who are largely dependent on the natural resources (Chattopadhyay, 2021). The climate change also has affected the livelihoods of nearly half of the population who are engaged in small-scale agriculture and this has negative impacts to the overall economy of the country.

In Bangladesh the impacts of climate change have been so evident that as a result the country is facing climate change induced extreme disaster events, such as: sea level rise, erratic rainfall, flooding, drought, cyclones, and salinity intrusion (Mojid, 2019). The disadvantageous groups of society suffer from the adverse effects of climate change induced natural disasters in three ways: a) the exposure of the vulnerable groups increases, b) susceptibility to damage increases and c) capacity to cope and recover decreases (Islamand Winkel, 2017). This framework can be applicable to illustrate the situation of inequality of Bangladesh.

However, the socio-economic inequalities have been accelerated due to the climate change induced natural disasters specially the changes occurred to the livelihood of the vulnerable communities. This situation is creating a constant insecurity and the political economy of the country endangers the poor communities who suffer most from the socioeconomic inequalities (Day and Caus, 2020).

From the literature review it is evident that there is a link between the inequality situation of the country and the natural disaster situation where the vulnerable groups tend to suffer most. In the next section of discussion and analysis the researcher will illustrate this link with the help of primary and secondary data.

\section{DISCUSSION AND ANALYSIS}

\section{Social Inequality Scenario of the Country}

Social impacts of the disasters include: 'the loss of life, injury, disease outbreaks, disruption of social services and malnourishment' and the economic impacts are: 'losses include the loss of livelihood, capital, infrastructure and communications, and the interruption of development programmes' (UNDRR, 2020). When we speak about social inequality it generally focuses on the distribution of goods and burdens of the society. The goods are: income, education, employment while the burdens are: abuse, criminality, unemployment and marginalization (Department of Sociology and Human Geography, University of Oslo, 2019). In this regard, to analyze the situation of the social inequality of Bangladesh we need to focus both on the goods and burdens of the country.

Income Inequality Situation of the Country: The research paper 'Inequality in Rural Bangladesh in the 2000s: Trends and Causes' by Osmani and Binayak Sen shows that the income inequality has been more prominent over the decade while the distribution of consumption remains unchanged which is widening the income inequality. The Household Income and Expenditure Survey (HIES) conducted by the Bangladesh Bureau of Statistics (BBS) was the primary source of data of this research. As the consumption rate is stable thus the inequality played an important role in the acceleration of poverty over the decade (2000 -2010) because the poverty is generally measured with consumption than income. Moreover, according to the GINI ${ }^{1}$ Coefficient income inequality increased from 0.35 in 2000 to 0.46 in 20210 and the consumption distribution remained constant at 0.28 (Figure 1) (Osmani and Sen, 2011).

\begin{tabular}{|c|c|c|c|c|c|}
\hline \multicolumn{6}{|c|}{$\begin{array}{l}\text { EVOL.TION OF INEQUALITY IN RERAL BANGLADESH: 1991/92-2010 } \\
\text { (Gini coefficient) }\end{array}$} \\
\hline Distribution of & $1991 / 92$ & $1995 / 96$ & 2000 & 2005 & 2010 \\
\hline Per capita mesme & 0.276 & 0310 & 0.365 & 0.404 & 0.465 \\
\hline Per capita consumption & 0.249 & 0277 & 0.281 & 0.280 & 0.291 \\
\hline
\end{tabular}

Figure 1: Per Capita Income and Per Capita Consumption According to GINI Coefficient

Source: Osmani and Sen, 2011

Link between Economic and Social Inequality: According to the 2016 HIES data released by BBS, the income shares of the poorest $10 \%$ household received $1.01 \%$ of the total national income which was $2 \%$ in 2010 compared to the richest $10 \%$ of the population who occupied $38.16 \%$ of national income in 2016 while the percentage was 35.84 in 2010 (Khan, 2018). This data indicates that the rich are becoming richer day by day and the polarization is

1 "Gini coefficient is named for Italian statistician and demographer Corrado Gini. On this scale, a score of zero represents total equality- a state in which every worker earns exactly the same. At the other end, a score of 100 represents total inequality- $a$ state in which all income is earned by one individual" (CFI, 2015). 
becoming so evident. In this country the causes of economic inequalities are quite similar like other countries. The main cause of economic inequality is the inequal distribution of wealth and human capital. Moreover, the same lies behind the social inequality where the unequal distribution of power structure also plays an important role. So, the social climbing opportunities are also limited for the vulnerable communities who tend to suffer from economic inequality. Here lies the link between economic and social inequality situation.

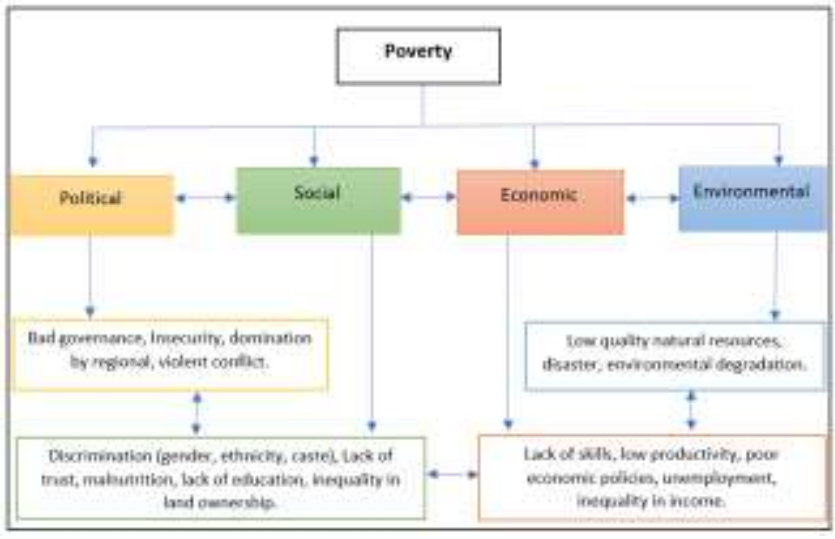

Figure 2: Links between the Drivers of Poverty

Source: Islam \& Omori, 2004

With reference from the Figure 2 as portrayed by Islam and Omori (2004) there is a clear link between the drivers of poverty (political, social, economic and environmental). According to the responses of the key interviews, each driver is linked with another and the overall vulnerability situation depends on the interrelation between these factors. They play a crucial role to determine the situation of the community people. The overall political economic situation has impacts on the distribution of wealth and capital where the social and environmental causes have direct and also indirect links to the overall situation of the vulnerability.

Livelihood, Vulnerability and Inequality: According to the responses of the key informants, the researcher tried to demonstrate the links between the inequality and vulnerability. Respondents have stated that, the disaster vulnerability is directly linked to the livelihood crisis especially in the disaster-prone areas. So, the unequal situation raises here especially between the people form more disaster vulnerable areas and the areas which are less vulnerable. People who are involved in the informal economy are the more vulnerable as their livelihood measures tend to be more affected by the natural disasters and the climate change induced disasters. As in rural Bangladesh there is always competition for scarce resources and the disasters sharp the unequal distribution of resources. So, there is always the risk of livelihood insecurity of the people of the vulnerable community. For example, coastal areas of Bangladesh are vulnerable due to the natural disasters and climate variability and the research by Kazi Ali Toufique and Mohammad Yunus titled 'Vulnerability of Livelihoods in the Coastal Districts of Bangladesh' shows that, the households of coastal areas are more vulnerable. Pictorial presentation of the findings is presented in Figure 3. According to this research, in coastal areas of Bangladesh, there is higher crop damage as well as the damage to livestock. Also, the houses are vulnerable and there are more injuries due to natural disasters (Toufique and Yunus, 2013). So, the overall livelihood patterns of the people are affected in the disaster-prone areas. So here lies the situation of inequality where the people of disasterprone areas tend to suffer more.

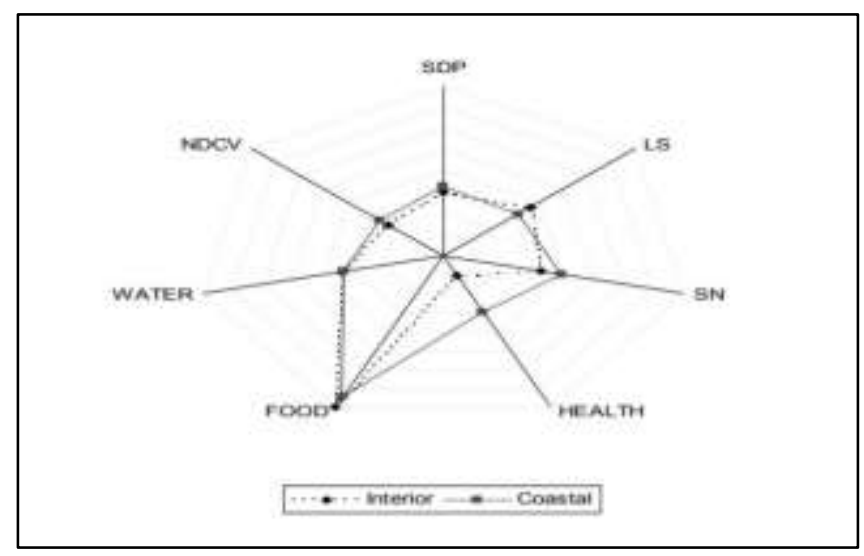

Figure 3: Vulnerability Spider Diagram of the Livelihood Vulnerability Index (LVI) for Interior and Coastal Regions

Source: Toufique \& Yunus, 2013

Disaster and Gender Inequality: Due to the disaster scenario of the vulnerable areas, the socially excluded and economically insecure people usually bear a disproportionate burden. The impacts of disasters are felt differently for men and women. And this accelerates the situation of inequality in a community as the impacts of disasters are often shaped by the gender dynamics as because of the cultural pattern of gender relationship in a community. According to a study it is revealed that, the rate of 
mortality of women from disasters is generally higher in the societies where women have unequal access to the socio-economic status. Unequal distribution of resources and structural inequality are the main causes behind the gender-based differentiation of disasters. This situation hinders the overall resilience of the community (Erman, et al., 2021). Conceptual Framework of Disaster Impacts and Gender Dynamics as portrayed by Erman et al. (2021) is presented in Figure 4.

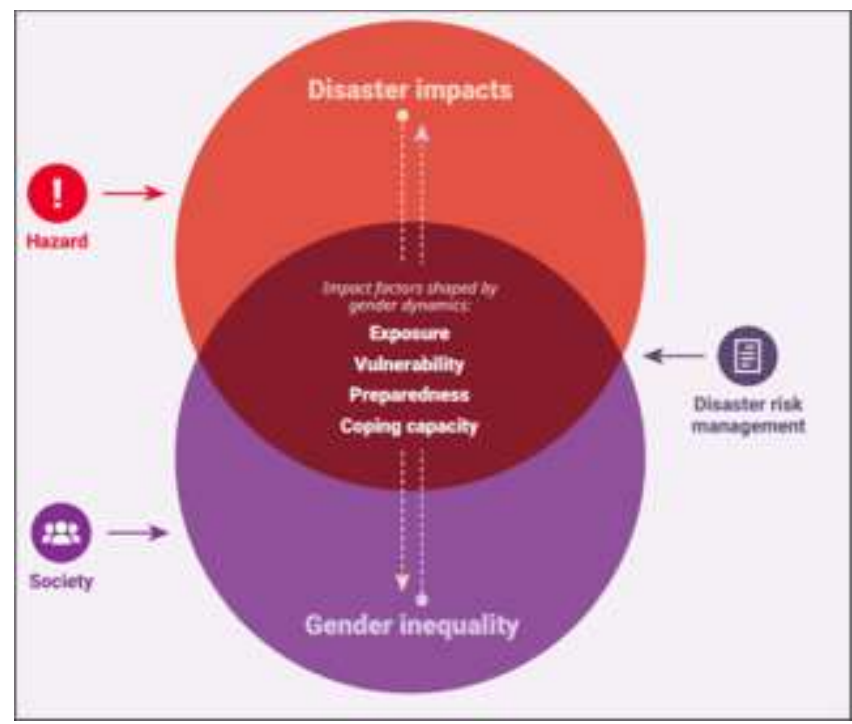

Figure 4: Conceptual Framework of Disaster Impacts and Gender Dynamics

Source: Erman et al. 2021

Respondents of the key informant interviews have demonstrated that the gender differentiation is visible at different levels of disaster process, such as: exposure to risk, risk perception, preparedness, response, recovery and reconstruction. The persistent pattern of gender inequality usually put women at risk during disasters. Informants have mentioned that the disaster fatality rates are higher for woman than men in Bangladesh. Traditional dress pattern and the tradition of maintaining long hair are one of the reasons of risk for women especially during floods and cyclones (Alam and Collins, 2010). According to several studies it is found that there is gender-based differences in the ability of swimming and climbing trees during emergency. Differentiated livelihood strategies also make women vulnerable to become resilient (UN Women and UNICEF, 2019). Moreover, among the vulnerable communities of Bangladesh where gender-based vulnerabilities are more evident in every aspect of social and economic sector there lies the risk of disasters which seems disproportionally high for women. Along with the biologically determined difference in disaster mortality the socially structured norms and values also put women in a disadvantageous position (Neumayer and Plümper, 2008). Traditional expectations and home-based responsibilities of women limit their opportunities for political involvement, education and access to information. So, they are trapped in the cycle of vulnerability. The gender-based inequality is rooted specially in economic, social, educational and political imbalances in all levels of the society. This situation of inequality increases the disaster risks for women in the vulnerable areas.

Healthcare and Education related Inequalities in Disaster-prone Areas: As to have an overall insight of the social inequality situation the status of the health and education facilities matters. In various literatures the consequences of social inequality are exposed mostly in terms of the lack of education and health care facilities among the vulnerable communities (United Nations Department of Economic and Social Affair, 2020). Informants have mentioned that, due to age and disability some vulnerable people remain excluded and become more vulnerable in the overall social setup of the communities of rural Bangladesh. Aged and disable (both physical and mental) people become sometimes invisible and marginalized because they are economically insecure. In disaster-vulnerable rural areas, they suffer a lot because of the lack of proper health facilities (SAMHSA, 2017). In Bangladesh over 19 million children do suffer from the adverse impacts of the climate change induced disasters (The Daily Star, 2021). Disease, outbreaks and epidemics immediately after natural disasters usually impact the poor more as the result of persisting inequalities (Collins, 2009). Children tend to suffer from health-related complexities (such as: malnutrition, early childhood health problems, unavailable vaccine facility, lack of primary health care and so on) especially among the vulnerable communities of disaster-prone areas. Women may suffer different negative reproductive health consequences following a disaster. The report of rapid gender analysis of Cyclone Amphan in 2020 reveals that, women tend to become mute over their reproductive and sexual health related decisions, such as: family planning and use of birth control (Plan International, 2021). 
Moreover, the education related challenges are also prevailing in the whole process of social inequality. Natural disasters, such as: cyclone, flood, riverbank erosion, storm surges and landslides do affect the education sector. Disasters do disrupt the educational process and infrastructure and pose challenges to the overall education systems of the vulnerable communities. According to the available data, more than 4,666 schools are affected by disasters per year and in recent years (from 2013-16) disasters, particularly cyclones have affected and disrupted the education of nearly 1.5 million children (Quayyum and Chowdhury, 2016). The natural disasters damage the infrastructure of the educational institutions of the vulnerable areas and many children along with their families tend to become displaced. This sort of situation creates negative impacts on the educational sector of the country (Relief Web, 2020). Due to the prevailing situation of social inequality and natural disasters the aged, women, children (other minor groups) and disable people do suffer on the verge of destitution and remain at risk.

Linking Disaster Risk Reduction (DRR) and Poverty Alleviation: From the previous discussion on the inequality scenario of the country it is very much evident that the disaster impacts have direct link with the present situation of destitution of the vulnerable communities. So, if there is an effective DRR measures to reduce the risk of disasters there will be a positive impact on the life of the people at risk. As the inequality situation of the disaster-prone areas have direct link with the poverty status of those communities so if there is effective measure to reduce disaster risk, it will definitely have positive impacts on the betterment of poverty scenario of the vulnerable communities. To reveal the link between DRR and poverty alleviation the researcher has collected data from available secondary sources. Also, the opinions of the key informants will be incorporated here.

As the economy of Bangladesh is mainly based on the agriculture, so the effective DRR strategies which are specially focused on the agricultural-level technologies and practices would be very much efficient to have a positive impact on the economy. As to alleviate poverty targeting the economic sector is the first and foremost step. In our country the effective DRR in the agro-economic sector might take some crucial steps in this regard, such as: first, smaller and incremental scale farmer to farmer replication; second, relevant policy and support from the government and non-government sector to replicate the good practices of DRR like other countries of the world. Some examples of good practices applicable to Bangladesh might be: livelihood diversification, agriculture related infrastructure development, introduce disaster tolerant crop varieties etc. These practices need to be applied to the geographical context of the 30 different Agro-Ecological Zones of Bangladesh (Bangladesh Agro Meteorological Information Portal, 2021). Also, the ecosystem-based livelihood diversification should be also focused in this context.

In the 2019 research report of FAO titled 'Disaster risk reduction at farm level: Multiple benefits, no regrets' there are the examples of good practices of DRR regarding the agronomic measures for farmers with both economic and social benefits. The report is comprised of the farm level effective DRR practices in Bolivia, Cambodia, Colombia, Guyana, Haiti, Jamaica, the Lao People's Democratic Republic, Pakistan, the Philippines, and Uganda. These examples can be applicable for similar ecosystems of Bangladesh for applying the similar type practices especially in the hazard vulnerable areas of different Agro-Ecological Zones of the country. If we can target the economy and livelihood factors through proper disaster risk reduction then the poverty alleviation process will be accelerated. In this literature the following measures are mentioned which can be replicated in rural Bangladesh:

a) Agronomic practices and adaptive measures towards disaster situations

b) Livelihood diversification

c) Introducing new and modified agricultural technology

d) Introducing flood and drought tolerant crop varieties and livestock

e) Crop specific practices

f) Livestock specific practices (Food and Agriculture Organization of the United Nations, 2019).

In a nutshell, the poverty reduction ultimately targets the economic growth. To generate economic growth in the disaster vulnerable communities there should be the continuous process of income generated growth (UNDP, 2004) which is generally hampered 
due to the disaster situation. According to the opinions of the key informants, to ensure the security and services to the vulnerable groups the proper steps should be taken through different plans and policies by both government and non-governmental organizations. In disaster vulnerable areas there should be the provision of alternative, improved and diversified livelihood strategies.

\section{DRR to Reduce Inequality: A Possible Way Forward}

Here the researcher has combined the available data from the existing relevant literature and the responses of the interviews. According to the opinions of the key informants, the effective DRR mainstreaming will be effective if all the social and cultural factors of communities are included in the overall risk reduction procedures. In all the steps of the cycle of DRR there should be the provision for human rights, community participation and community empowerment. In each step of DRR the cultural relativism should be considered as each community has their own values and way of life. Also, DRR steps should always promote gender equality especially when the communities are being involved directly, such as during the CRA (Community based Risk Assessment) gender equality could be a priority for the researcher and the facilitator.

In rural Bangladesh the excluded groups are usually comprised with women, children, aged people, indigenous people, religious minority, landless tenants and so on. According to the research of GFDRR, the main causes of their vulnerability are: 'geographical context; their financial, socioeconomic, cultural, and gender; and in their lack of or restricted access to public services like health care and education, information, decision making, and justice' (Arnold and Cosmo, 2015). To reduce the inequality of the disaster-prone areas the effective resilience building through effective DRR measures will be more pragmatic and practical option as in these areas disasters and the inequality has a symbolic relationship. Disasters make the inequality situation more adverse and the people of these areas become vulnerable due to their lack of capacity. Inclusive principle should be regarded here to reduce the inequality and this inclusive measure will ensure the resilience in the long run for the vulnerable communities. The mentioned excluded groups should be considered in every policy and program of DRR. In this regard, the area and sector specific DRR measures should be followed here. In the following table (Table 1) the sector specific DRR considerations are mentioned:

Table 1: Key DRR Elements and Examples of Sector Specific DRR Measures

\begin{tabular}{|c|c|}
\hline Key Factors & $\begin{array}{l}\text { Example of Sector-Specific } \\
\text { DRR Considerations }\end{array}$ \\
\hline $\begin{array}{l}\text { Risks } \\
\text { (Emerging/Immediate): }\end{array}$ & $\begin{array}{l}\text { Risks which are emerging in a } \\
\text { sector because of a disaster } \\
\text { and requires immediate } \\
\text { attention. Example: repairing } \\
\text { the shelter houses can serve } \\
\text { the purpose of education } \\
\text { facilities or cleaning the trash } \\
\text { of agricultural land might lead } \\
\text { to the rehabilitation and food } \\
\text { security. }\end{array}$ \\
\hline $\begin{array}{l}\text { Early Warning and } \\
\text { Risk Communication: }\end{array}$ & $\begin{array}{l}\text { Early warning systems in each } \\
\text { sectors need proper repairing, } \\
\text { for example: nutrition and } \\
\text { food security monitoring, } \\
\text { disease surveillance etc. }\end{array}$ \\
\hline $\begin{array}{l}\text { Underlying } \quad \text { Risk } \\
\text { Factors }\end{array}$ & $\begin{array}{l}\text { In the process of recovery, the } \\
\text { underlying risk factors should } \\
\text { be addressed as these risk } \\
\text { factors contributed in disasters } \\
\text { within different sectors. Such } \\
\text { as: lack of required building } \\
\text { code for different } \\
\text { infrastructures (example: } \\
\text { hospitals, schools etc.), } \\
\text { environmental degradation, } \\
\text { unsustainable agricultural } \\
\text { practices etc. }\end{array}$ \\
\hline Preparedness & $\begin{array}{l}\text { The measures which were not } \\
\text { taken as preparedness steps } \\
\text { before the disaster and has } \\
\text { impacts within the sectors, for } \\
\text { example: evacuation plan for } \\
\text { community, contingency } \\
\text { plans, temporary shelters for } \\
\text { displaced population etc. }\end{array}$ \\
\hline Risk governance & $\begin{array}{l}\text { Capacity-building measures } \\
\text { needed to ensure sector } \\
\text { ministries have the guidance, } \\
\text { expertise, training, practical } \\
\text { tools, infrastructure and } \\
\text { equipment, policies and } \\
\text { overall institutional capacity to }\end{array}$ \\
\hline
\end{tabular}




\begin{tabular}{|l|l|}
\hline Building back better & $\begin{array}{l}\text { integrate DRR into sector } \\
\text { recovery plans and to } \\
\text { implement these effectively. }\end{array}$ \\
\hline $\begin{array}{l}\text { Defining key elements for } \\
\text { sector specific recovery which } \\
\text { are sustainable for build back } \\
\text { better, for example: } \\
\text { maintaining building codes, } \\
\text { safe location points for } \\
\text { hospitals and schools, } \\
\text { sustainable design plan, } \\
\text { required agricultural } \\
\text { technology, eco-friendly } \\
\text { farming practice, restoring } \\
\text { biodiversity, conservation of } \\
\text { ecosystems, resource } \\
\text { management and so on. }\end{array}$ \\
\hline Costing & $\begin{array}{l}\text { An appropriate budget for } \\
\text { Disaster Risk Reduction } \\
\text { (DRR) for build back better } \\
\text { for sector specific recovery } \\
\text { and reconstruction plans by } \\
\text { identifying necessary risk } \\
\text { factors. }\end{array}$ \\
\hline
\end{tabular}

Source: GFDRR, 2014

From the Table 1 it is evident that, the sector specific key DRR elements of each key factor might be an effective way forward for mainstreaming DRR. These key steps with adequate budget and policies would be possible solution of reducing the inequality situation of the vulnerable people. For effective DRR measures there should be a bridge between communities and the government. Poor and marginalized communities should be empowered enough to narrate their own destitution and to propose their way forward and the solutions by themselves. Indigenous knowledge and traditional coping strategies also should be considered while implementing the DRR steps.

Moreover, to ensure the sustainable DRR policies and programs both the economic and social inequalities should be considered. To make the DRR strategies sustainable in vulnerable communities reducing inequality is crucial. For this there should be minimum living wage, improved living conditions, and food security to accelerate the capacity of the vulnerable population for the disaster-prone areas of Bangladesh. The DRR process, assessment and analyses should not only focus on the gender issue (important axes of social inequality) but also the other aspects of social inequality, such as: age, disability, education, health, ethnicity, socio-economic status, religious minority and so on. If the proper DRR policies steps are taken on a sectorial basis (Table 1) to reduce the vulnerability of the rural communities then this might be a possible solution to reduce the inequality situation (both economic and social).

\section{CONCLUSION}

In conclusion it can be summarized that natural disasters buffer the both social and economic inequality situation of the vulnerable communities. As a result, the disasters hinder the capacity development and cause impoverishment where the cycle of loss traps the people at risk and slow their efforts to reduce poverty. The disaster vulnerable areas of Bangladesh are usually comprised of the poor population of rural areas where they have the lowest capacity to cope. They do depend on the subsistence agriculture for their livelihood and the natural disasters cause a huge loss to the livelihoods. During emergency they are affected by the cost of response and this situation gets worse by the persistent pattern of inequality of the society. The present study highlighted the overall inequality situation of the rural disaster-prone areas of Bangladesh. Both the scenario of economic and social inequalities is narrated here. The present study has showed that if the DRR measures are effectively taken in the vulnerable areas then the inequality situation would be reduced. This study also showed that, the effective DRR measures can be linked with the poverty reduction. Also, with proper sectoral DRR steps the social inequality situation might get improved. DRR measures directly have a link with the capacity building process and the improved capacity of the communities can reduce vulnerability as well as risks. So effective DRR can be a possible way forward towards the reduction of inequality along with other essential economic and social protection steps to be taken by the government. As the Disaster Risk Reduction measures are usually taken to reduce the vulnerability so the DRR planners should consider these vulnerable communities while planning to cope, manage and recover from the risks of disasters. In conclusion in can be said that, in rural Bangladesh, the DRR interventions should follow the inclusive measures where the local people can be empowered enough to become resilient. 


\section{REFERENCES}

Ahmed, A. U., Haq, S., Nasreen, M. \& Hassan, A. W. R. (2015). Climate Change and Disaster Management, Planning Commission, Government of the People's Republic of Bangladesh, Dhaka.

Arnold, M. and Cosmo, S. D (2015). Building Social Resilience: Protecting and Empowering Those Most at Risk, The World Bank, Washington DC.

ACS AEC (2017). Inequality and its impact on the resilience of societies. [Online] Available at: http://www.acsaec.org/index.php?q=disaster-risk-reduction/inequalityand-its-impact-on-the-resilience-of-societies [Accessed 16 June 2021].

Alam, E. and Collins, E. (2010). Cyclone disaster vulnerability and response experiences in coastal Bangladesh. Disasters, 34(4):. 6.

Bangladesh Agro Meteorological Information Portal (2021). AGRO-ECOLOGICAL ZONES -AEZS MAPS. [Online]

Available at: https://www.bamis.gov.bd/en/page/aezsmaps/

[Accessed 10 December 2021].

Beck, T. (2005). Learning Lessons from Disaster Recovery: The Case of Bangladesh, The World Bank, Washington.

CEIC (2016). Bangladesh BD: Gini Coefficient (GINI Index): World Bank Estimate. [Online]

Available at:

https://www.ceicdata.com/en/bangladesh/poverty/bdgini-coefficient-gini-index-world-bank-estimate [Accessed 7 December 2021].

CFE-DM (2020). Bangladesh Disaster Management Reference Handbook, CFE-DM, Dhaka.

CFI (2015). What is the Gini Coefficient?. [Online] Available at: https://corporatefinanceinstitute.com/resources/knowle dge/economics/gini-coefficient/

[Accessed 20 September 2021].

Chattopadhyay, S. (2021). Bangladesh: Much More to Do to Tackle Inequality. [Online]

Available at: https:// thewire.in/south-asia/bangladeshmuch-more-to-do-to-tackle-inequality

[Accessed 2 October 2021].

Chowdhury, M. N. M. \& Hossain, M. M. (2019). Poverty, Income Inequality and Growth in Bangladesh: Revisited Karl-Marx. American Finance \& Banking Review, 4(2).
Collins, A. (2009). The meaning of health security for disaster resilience in Bangladesh: Full Research Report, DFID, Swindon.

Day, A. and Caus, J. (2020). Conflict Prevention in an Era of Climate Change: Adapting the UN to ClimateSecurity Risks, United Nations University, New York.

Department of Sociology and Human Geography, University of Oslo (2019). Social Inequality. [Online] Available at: https://www.sv.uio.no/iss/english/research/researchareas/social-inequality/

[Accessed 16 September 2021].

Erman, A., Robbe, S.A.D.V. and Kabir, S.F.T. (2021). Gender Dynamics of Disaster Risk and Resilience, World Bank, Washington DC.

ESCAP (2017). Mainstreaming Disaster Risk Reduction for Sustainable Development: A Guidebook for the AsiaPacific, United Nations, Bangkok.

Food and Agriculture Organization of the United Nations (2019). Disaster risk reduction at farm level: Multiple benefits, no regrets, FAO, Rome.

Galagedarage, G. M. (2019). The Use of Information and Communication Technologies (ICTs) for Natural Disaster Management in Sri Lanka, The International Journal of Interdisciplinary Global Studies, 14(2): 31.

GFDRR (2014). Disaster Risk Reduction, The World Bank, Washington DC.

Govt. of Bangladesh (2012). Most disaster-prone districts in Bangladesh. [Online]

Available at:

https://reliefweb.int/map/bangladesh/most-disasterprone-districts-bangladesh [Accessed 12 September 2021].

Islam, M. T. \& Omori, K. (2004). Inequality, Poverty and Agriculture in Rural Bangladesh: Perspective from a Village Study. J-STAGE, p. 25.

Islam, N. \& Winkel, J. (2017). Climate Change and Social Inequality, Department of Economic \& Social Affairs, UN, New York.

Khan, S. (2018). Rising inequality in Bangladesh. [Online] Available at: https://bdplatform4sdgs.net/risinginequality-in-bangladesh/

[Accessed 21 September 2021].

Khondker, D. B. H. (2014). Poverty, Vulnerability and Inequality in Bangladesh, Dhaka: Planning Commission, Government of Bangladesh. 
Mojid, M. A. (2019). Climate change-induced challenges to sustainable development in Bangladesh, IOP Publishing Ltd, Yogyakarta.

Neumayer, E. and Plümper, T. (2008). The Gendered Nature of Natural Disasters: The Impact of Catastrophic Events on the Gender Gap in Life Expectancy, 1981-2002. Annals of the American Association of Geographers, 97(3).

Osmani, S. R. and Sen, B. (2011). Inequality in Rural Bangladesh in the 2000s: Trends and Causes. Bangladesh Development Studies, 34 (4).

Plan International (2021). Study on Women and Girls' Participation in Community Disaster Risk Management in Bangladesh, s.1.: Rapid Asia.

Quayyum, M. A. \& Chowdhury, O. M. A. (2016). Natural disasters and uninterrupted education. [Online] Available at: https://www.thedailystar.net/oped/natural-disasters-and-uninterrupted-education1280044

[Accessed 22 September 2021].

ReliefWeb (2020). In rural Bangladesh, a journey to school-led disaster risk reduction begins. [Online] Available at: https://reliefweb.int/report/bangladesh/ruralbangladesh-journey-school-led-disaster-risk-reductionbegins [Accessed December 2021].

SAMHSA, 2017. Greater Impact: How Disasters Affect People of Low Socioeconomic Status, SAMHSA, Maryland.

The Daily Star (2021). Climate Disasters: $19 m$ children face risks in Bangladesh. [Online]
Available

at:

https://www.thedailystar.net/frontpage/climate-

disasters-19m-children-face-risks-bangladesh-1817422 [Accessed 10 December 2021].

Toufique, K. A. and Yunus, M. (2013). Vulnerability of Livelihoods in the Coastal Districts of Bangladesh. Bangladesh Development Studies, 36 (1): 108-111.

UN Women and UNICEF, (2019). Gender and Age Inequality of Disaster Risk, UN Women, Geneva.

UNDP (2004). Poverty Reduction \& Disaster Risk Reduction, BCPR \& UN/ISDR Africa, CapeTown.

UNDRR (2020). Disaster Risk Reduction in Bangladesh, ADPC, Bangkok.

UNDRR (2020). Disaster Risk Reduction in Bangladesh Status Report 2020, UNDRR, Bangkok.

UNDRR (2020). Integrating Disaster Risk Reduction and Climate Change Adaptation in the UN Sustainable Development Cooperation Framework, United Nations, Geneva.

UNDRR (2021). Disaster risk reduction. [Online] Available at: https://www.undrr.org/terminology/disaster-riskreduction [Accessed 10 July 2021].

United Nations Department of Economic and Social Affair, 2020. Inequality in a Rapidly Changing World, United Nations Publication, Geneva.

World Bank Press Release (2018). Bangladesh Disaster Risk and Climate Resilience Program, World Bank. 